\title{
Integrating Chaotic Perspective and Behavioral Learning Theory into a Global Pandemic Crisis Management Framework for Hotel Service Providers
}

\author{
Dung Le, ${ }^{a}$ Giang Phi, ${ }^{a}$ Truc Le ${ }^{b}$ \\ ${ }^{\mathbf{a}}$ College of Business and Management, VinUniversity, Hanoi, Vietnam 008404; ${ }^{\mathbf{b}}$ Department of Tourism, Hospitality and Sport Management, \\ Griffith University, Australia \\ Contact: dung.ltp@vinuni.edu.vn, iD https://orcid.org/0000-0002-3578-5392 (DL); giangphi@duytan.edu.vn, \\ (iD https://orcid.org/0000-0002-3578-5392 (GP); truc.le@griffith.edu.au, (iD https://orcid.org/0000-0002-3578-5392 (TL)
}

Received: December 15, 2020

Revised: May 12, 2021

Accepted: July 1, 2021

Published Online in Articles in Advance:

[0] 2021

https://doi.org/10.1287/serv.2021.0282

Copyright: ๑ 2021 INFORMS

\begin{abstract}
Hotel service providers are among the most affected by the evolving Covid-19 pandemic. Although the consequences of the pandemic on hotel operations have been widely examined, the question of how hotel businesses can revive, innovate, and transform in order to survive and recover remains vastly under-researched. This study aims to provide insights on this important topic by analyzing 312 news articles between December 1 , 2019, and March 1, 2021, published by global news media, which report hotels' strategies and tactics to deal with the pandemic. Grounded on chaos theory, behavioral learning theory, and an integrated crisis management model, a global pandemic crisis management framework is developed. Practically, the paper reveals best practices applied by hoteliers to deal with the pandemic (e.g., service transformation, smart marketing, strategic collaboration/alliance, mergers and acquisitions, and digitalization) and suggests ways for hotel services providers to adapt to the "new travel" age.
\end{abstract}

History: Saif Benjaafar served as editor-in-chief for this article. Marshall Fisher, Andy Neely and Rohit Verma served as guest editors. This paper has been accepted for the Service Science Special Issue on Reimagining the Science of Service in a Post-Pandemic World.

Keywords: Covid-19 • hotel services $•$ Leximancer $\bullet$ news media $•$ service innovation $\bullet$ pandemic crisis management $\bullet$ chaos theory

\section{Introduction}

Owning to tourism booming in the last few decades, hotel services have become one of the fastest growing sectors within the service economy. However, the Covid-19 pandemic disrupted hotel development trends and still threatens its recovery despite the availability of some vaccines (Yang et al. 2021). Historically, the tourism and hospitality sectors are frequently disrupted by various types of crises caused by natural disasters, epidemics, political conflicts, war, terrorism attacks, or financial crises. However, this global pandemic's consequences could outweigh all the previous crises combined, including the 9/11 terrorism attack, 2008 recession, and SARS epidemic (Oxford Economics 2020).

It is challenging for hotel service providers to adopt previous crisis management models as practical responses to this current global pandemic crisis. First, previous crisis management models are somehow outdated. Ritchie and Jiang (2019) review 142 papers on this topic between 1960 and 2018 and find that empirical studies testing risk/crisis management models for tourism and hospitality stakeholders were mostly conducted more than 10 years ago. Hence, Mair et al.
(2016) emphasize the necessity of advancing the existing literature by further refining and testing risk/crisis management in new contexts. Also, these models suggest "one size fits all" guidance although crises vary in duration, scale, and impact (Speakman and Sharpley 2012). Hence, a detailed crisis management plan based on past crises may not necessarily be effective for hotels in dealing with the complex and evolving crisis (Paraskevas 2006).

Second, the Covid-19 pandemic is forecasted to be followed by a global recession (Felsenthal 2020). The coexistence of potentially multiple crises creates a chaotic and complex environment for hotels to function. Multiple crises are recorded in hotel history, for example, the case of the 9/11 terrorist attack and the global financial crisis of 2008 (Kubickova et al. 2019), the global financial crisis and Swine flu in the United Kingdom (Page et al. 2012), and an economic meltdown and escalating political crisis in Greece (Cohen and Neal 2010). In case of multiple crises, a chaotic perspective is necessary to guide hotel managers to navigate, revive, and thrive (Speakman and Sharpley 2012, Pappas 2018). 
Third, the global Covid-19 pandemic, which has severely impacted hotel service providers around the globe, requires a global investigation. Meanwhile, previous health-related crisis research mostly focuses on investigating hotels' responses in a specific region, such as Western Africa during the Ebola epidemic (Novelli et al. 2018, Maphanga and Henama 2019), or some countries during the SARS epidemic in 2002-2004 (Henderson and Ng 2004, Leung and Lam 2004, Kim et al. 2005, Cooper 2006, Lo et al. 2006, Jayawardena et al. 2008) or, recently, a country, for example, China, in the first phase of the Covid-19 infection (Hao et al. 2020). Although some existing guidelines for protocols may have been developed in relation to a local/regional health crisis, it becomes critical to develop a global overview and identify best practices in the hotel sector to deal with a global pandemic of unprecedented magnitude.

Against this background, this paper addresses the aforementioned knowledge gaps by developing a pandemic crisis management model for hotel service providers to better address the evolving, complex, and chaotic environments caused by the Covid-19 pandemic. Specifically, the aim of this paper is to critically explore how hotel businesses can revive, innovate, and transform in order to survive and recover post-COVID-19. Utilizing global news media sources, hotels' strategic responses to the pandemic from December 1, 2019, to March 1, 2021, are identified and analyzed. The analysis of news media can produce important insights into contemporary issues because of news media's timely reports on actors' responses to evolving situations all over the globe (Schweinsberg et al. 2017, Phi 2019). A pandemic crisis management framework is then refined based on previous crisis management models (Wang and Ritchie 2011, Ritchie 2004), chaos theory (McKercher 1999, Zahra and Ryan 2007, Speakman and Sharpley 2012, Pappas 2018), and current hotel strategic responses to the pandemic. This paper, thus, contributes to the development of guidelines and protocols for the hotel service sector in the "new travel" age.

This paper argues that, instead of crisis management planning, adopting a chaotic perspective and continuous learning approach are essential for hotel managers to proactively adapt to global pandemic situations. The importance of a crisis-readiness strategy and the role of a crisis as a breeding ground for service transformation/innovation in the hotel sector are highlighted. Key aspects of hotel services operations (i.e., marketing, finance, human resources management, and digitalization) collectively contribute to a hotel survival and recovery strategy in pandemic crisis situations. Hotel service providers can still find opportunities induced by challenges and uncertainty during the pandemic and rely on service transformation/innovation to secure a strong competitive advantage.

\section{Literature Review}

\subsection{Integrated Crisis Management Approach}

A crisis can be defined as a "disruption that physically affects a system as a whole and threatens its basic assumptions, its subjective sense of self, its existential core" (Pauchant and Mitroff 1992, p. 15). Hence, crisis management includes all necessary operations to be well prepared before the crisis strikes and to effectively respond to and quickly recover from a crisis ( $\mathrm{Yu}$ et al. 2005). Early crisis management research suggests a life-cycle crisis management approach, including three phases: pre-event, emergency, and postevent (Fink 1986). Later, Faulkner (2001) adapted six phases (pre-event, prodromal, emergency, intermediate, long-term, and resolution) for better planning, implementation, and evaluation of crisis management actions and strategy. Faulkner's (2001) life-cycle crisis management model has been widely applied in later crisis management studies to understand and explore the evolution of crises and corresponding reactions of tourism and hospitality organizations (Henderson and Ng 2004, Pforr and Hosie 2008).

The second approach to crisis management is labeled "action-based" or 4Rs (reduction, readiness, response, and recovery) (Wilks and Moore 2004). An action-oriented crisis management plan helps business managers to eliminate the likelihood of humaninduced crises (Pearson and Mitroff 1993). However, the adoption of this approach in hospitality businesses remains limited.

The third approach to crisis management includes three primary strategic stages: formation, implementation, and evaluation (Preble 1993). This strategic approach argues for the importance of proactive strategies (mitigation, preparedness, and warning) in addition to reactive strategies (impact assessment, crisis communication, recovery marketing, and stakeholder collaboration) (Ritchie and Jiang 2019).

The latest approach to crisis management consists of an integration of all three approaches for effective crisis management. The advantage of such an integrated approach is to offer a holistic view of crisis management with detailed strategies and action plans. Proactive (reduction and readiness plans) and reactive strategies (response and recovery actions) are recommended in each specific stage of crisis management (Moe and Pathranarakul 2006, Huang et al. 2008).

However, the integrated approach still relies on a somewhat linear crisis life cycle, assuming a start and end of any crisis that hotel service providers have to face. In other words, the crises are often assumed as happening separately, and the organization can 
effectively address one crisis at a time. In reality, hotel businesses function in a chaotic and complex environment in which multiple crises may strive and overlap (McKercher 1999, Zahra and Ryan 2007, Kubickova et al. 2019). For example, although tourism and hospitality businesses in Greece may have experienced and learned from a number of short and separate crises in the past, they were not well prepared when multiple crises of different natures took place continuously and at times concurrently over a prolonged period of nearly one decade (e.g., the 2007-2008 global financial crisis, followed by national economic recession and national social and political crises).

Further, the variations in business scales and compositions of hotel businesses also mean that they often have fewer resources allocated for risk management (Baggio 2008). In the context of the Covid-19 pandemic, Le and Phi (2021) argue against the adoption of a linear framework and highlight the importance of contextual factors (i.e., hotel sizes, hotel resources, and government regulations/support) as having strong influences on hotel businesses' actions. Longterm forecasting and crisis management planning are, thus, generally not applicable as one-size-fits-all because of these varied factors (Pappas 2018). Chaos/ complexity theory, therefore, may help direct hotel businesses' adaptive responses to deal with shocks and crises (Ritchie and Jiang 2019), which, in turn, enhances their flexibility and resilience to unprecedented and evolving crisis situations, such as the global Covid-19 pandemic.

\subsection{Chaos Theory}

Chaos theory was developed in the natural sciences during the 1970s and in the social sciences during the 1980s (Murphy 1996). The theory denies the predictability of systems and suggests that any triggering event may initiate directly or indirectly a crisis through the so-called "butterfly effect" (Speakman and Sharpley 2012). Evolved from chaos theory, complexity theory has been used to deal with complex systems that have many interacting agents and that are hard to predict (Zahra and Ryan 2007). In response to the strong relationship between chaos and complexity, the concept of a "chaotic system" is introduced to emphasize the character of complex systems as chaotically ordered entities (Pappas 2018).

Researchers generally agree that hotel service providers function in a tourism and hospitality system that is highly complex, unpredictable, and dynamic (McKercher 1999, Zahra and Ryan 2007, Olmedo and Mateos 2015). This is partly because of the "inseparability" characteristic of these sectors in which the production and offering of services cannot be separated from customers' simultaneous on-site consumptions (Moker et al. 2020). In addition, hotel businesses often rely on public resources (e.g., existing infrastructure, natural attractions, cultural capital) and have strong potential to generate both positive and negative economic, sociocultural, and environmental impacts at the destinations. They, thus, cannot operate in silo, but are embedded in a complex network of diverse stakeholders at local, regional, nation$\mathrm{al}$, and international levels, each having different interests and able to take uncoordinated actions (Phi et al. 2014). Hotel service providers, therefore, are highly susceptible to external factors and pressures in the wider operating environment (i.e., economic recession, epidemics, natural disasters, terrorist attacks, (trade) wars, foreign policies, and political conflicts). In this context, a chaotic perspective brings some concepts that can be beneficial to improve current crisis management models of hotel service providers: irreversible time and constant changes, nonlinearity and unpredictability, bifurcation and cosmology, and selforganization and strange attractors.

2.2.1. Irreversible Time and Constant Changes. As a chaotic system, the tourism and hospitality sector is continuously evolving in irreversible time (Olmedo and Mateos 2015). A chaotic system does not reach a stable equilibrium and can never pass through the same exact state more than once (Levy 1994). Despite some periods of stability or equilibrium, its existence is always on the edge of chaos. When unpredictable events, such as a crisis (e.g., natural disaster, economic recession, etc.), impact the stability and balance of the tourism and hospitality system, chaotic environments lead to a new level of balance. Therefore, the whole system may not return to the "old normal" situation as parts of the system are likely to have changed (Scott et al. 2008).

2.2.2. Nonlinearity and Unpredictability. Chaotic systems are not linear in nature, but are open systems and influenced by complex interactions and interrelationships (Olmedo and Mateos 2015). In chaotic systems, small disturbances (i.e., triggering events) can multiply over time and cause significant changes (Thietart and Forgues 1995, McKercher 1999). The nonlinearity makes long-term forecasting and planning almost impossible although it is still possible to describe the overall dynamics of the system (Baggio 2008). Therefore, the occurrence and magnitude of crises are often unpredictable, but it remains feasible to expect a crisis at some time (Ghaderi et al. 2014, Ritchie and Jiang 2019).

2.2.3. Bifurcation. Bifurcation can be defined as "an abrupt change in the long-term behavior of a system when the value of a constant is changed from below to above some critical value" (Lorenz 1995, p. 206). 
Bifurcation, thus, represents the flashpoint of change at which a system's direction and/or structure are fundamentally disrupted (Sellnow et al. 2002). Crises are just considered as points of system bifurcation, marking the period of chaos and disequilibrium (Speakman and Sharpley 2012).

2.2.4. Self-Organization and Strange Attractors. In order to deal with inevitably unprecedented crises, tourism and hospitality businesses must "self-organize and self-renew, with periods of order broken by sudden transformations whose direction has elements of chance and cannot be reversed" (Murphy 1996, p. 96). Following bifurcation, hotel service providers can make essential improvements through self-organization and creativity compared with precrisis conditions (Speakman and Sharpley 2012). At the heart of the self-organization process, strange attractors consist of points toward which a system tends to move: a goal, either deliberate or constrained by system parameters (Saunier and Meganck 2004). Strange attractors can take the form of a common vision, sense of meaning, strategy, or value system that drives people to achieve a common goal (Zahra and Ryan 2007). By providing communication platforms and encouraging cooperative relationships, hotel managers can facilitate the emergence of these strange attractors to assist the complex tourism system in moving toward relative stability following bifurcation (Speakman and Sharpley 2012).

\subsection{Behavioral Learning Theory}

The adaptability of each organization to chaos and shocks, however, also depends on the knowledge retained from past events, which can be considered as a "portfolio" of risk management. As a result, this paper incorporates learning theory, specifically behavioral learning theory (Skinner 1965, Rothschild and Gaidis 1981), which focuses on the idea that (organizational) behaviors are learned through interaction with the environment. Considering that the hotel sector is highly dependent and susceptible to the external environment, using behavioral learning theory helps validate and reinforce the organizational knowledge retained from past shocks and crises (Haleblian and Finkelstein 1999).

Essentially, in education, behaviorists believe learning is provided by a change in actions through an explorative process. The most common practice of behavioral learning theory is that external stimuli are paired with good performance and/or attitude, in other words, with the observable change in behavior (Guney and Al 2012). This theory is deemed applicable for the organizational learning process to deal with shocks and crises for two reasons. First, the change in the organizational behavior is observable (i.e., whether the risk is mitigated or avoided)
(Rothschild and Gaidis 1981). Second, the external stimuli for businesses can include tangible outcomes, such as increased profitability or harm and loss (thus, cost) reduction as a result of the mitigation or elimination of the risks involved (Whitten et al. 2010). As a result, businesses are stimulated to learn as they go from the past and current crisis events by using reduction measures and improving them simultaneously. This notion has a crucial implication for the revision of crisis management framework because the shocks are constantly changing (i.e., Covid-19 with various mutant strains with accelerated infection rates), which demands tourism and hotel operators to respond actively and simultaneously to adapt with the changing environment.

In sum, the elements of chaos theory (i.e., irreversible time, nonlinearity and unpredictability, bifurcation, and self-organization and strange attractors) and learning theory provide a firm basis to explore the emergent challenges and opportunities during the pandemic for hotel businesses. From a chaotic perspective, crisis management seeks to facilitate a selforganization process that enables hotels to adapt to unpredictable and complex environments (Olmedo and Mateos 2015). The implications of behavioral learning theory are crucial for the simultaneous learning and adapting process resulting from the everchanging environment and crises, which complement chaos theory. The remainder of this paper focuses on identifying and analyzing the elements of chaos and learning theory in the context of the Covid-19 pandemic and relies on these elements to refine the pandemic crisis management model.

\section{Methodology}

LexisNexis (one of the world's largest electronic databases for news and public records) was used to collect global news articles related to hotel responses to the Covid-19 pandemic. The search was conducted using the keywords "coronavirus" or "COVID-19" and "hotel or resort or hostel" and "strategies or solutions or responses." One filter layer was added using the connector " $\mathrm{W} / 5$ " to identify all documents in which the terms "strategies or solutions or responses" were located within a maximum of five words from the terms "hotel/resort/hostel." Only printed English news articles published in leading international/ national newspaper outlets were included to filter potentially fake news. Global news collected between December 1, 2019, and March 1, 2021, were classified into four different periods: (1) from December 1, 2019, to February 29, 2020, as the prepandemic crisis period; (2) from March 1, 2020, to May 31, 2020, since the World Trade Organization declared the Covid-19 a Q:12 global pandemic crisis; (3) from June 1, 2020, to 
August 31, 2020 with businesses reopening and a short recovery period, and (4) September 1, 2020, to March 1, 2021, as the second wave pandemic period for hotel learning and adaptation. The database was then further screened to remove irrelevant articles and duplicates, which resulted in a data set of 312 articles: pre-global crisis period (12 articles), global pandemic crisis (128 articles), hotel reopening in "new normal" conditions (96 articles), and continuous learning and adaptation in new travel period (76 articles). The volume of news articles in each period partly reflects the public interest in this topic over time in each region (see Table 1).

Content and thematic analysis are frequently used to analyze large data sets of documents and other communication artifacts, such as texts, pictures, audio, or video (Phi 2019), which makes the method relevant for the analysis of written global news media in this study. First, automated content analysis was employed, utilizing Leximancer software. In contrast to a human coding process that may have a higher chance of cognitive bias, Leximancer enables new insights and reflections on the examined topic by automatically identifying key concepts and generating visual concept maps (Scott et al. 2017). Content analysis via Leximancer, thus, provides a systematic, replicable approach to interpret and code a large volume of textual data based on word frequency and relationships between words (Phi 2019). In order to achieve interpretable results, the researchers followed a rigorous procedure. First, noninterpretable words, such as "according," "for," and "the" were deleted. Next, words of similar meanings, such as "coronavirus" and "covid" were grouped and coded as one concept, and relevant concepts were visualized into major themes to capture some important insights into the investigated topic (Le et al. 2019). An abductive approach was applied during the manual coding process with the support of Leximancer software, in which the authors were primarily guided by key themes identified by Leximancer and elements of chaos theory but still gave room for emerging themes (if any), especially in relation to hotel strategic responses. This triangulation of multiple approaches to analyzing the data set contributes to enhance the credibility of the findings (Oppermann 2000).

\section{Findings}

Given that the data set consists of four data sheets, Leximancer was run four times for each data sheet to analyze the main discussion themes on global news media at each pandemic crisis stage.

\subsection{Hotels' Proactive Measures at the Precrisis Stage}

The appearance of the Covid-19 virus consisted of a triggering event, which breaks the temporary balance of the whole hotel sector (i.e., the old normal in chaos theory; Murphy 1996). The first concept map (Figure 1) was generated by Leximancer using global news articles published between December 1, 2019, and February 29,2020, showing three main themes in order of importance: impact on hotels (92 occurrences), hotels' proactive measures (74 occurrences), and virus outbreak (33 occurrences). As shown in Figure 1, in this pre-global Covid period, the virus outbreak in Wuhan and the lockdown policy applied by the Chinese government to control the outbreak were two stories that attracted a lot of media attention. As the lockdown in Wuhan continued, more hotels and resorts in China were forced to be closed although hotel service providers in other countries were also impacted by a significant reduction in the number of Chinese tourists who canceled their travel.

Even though the occurrence of a pandemic disaster maybe difficult to predict and/or prevent (Ritchie 2004), early symptoms of the pandemic led to some proactive responses of hotel service providers. An asset-light strategy was implemented by some hotel chains, especially those in close proximity to Wuhan, such as Macau to release billions in funds for investors (see proactive measures in Figure 1). Manual coding revealed that, in order to deal with cash flow shortage problems, hotel chains, such as MGM China or Lemon Tree Hotels, sold real estate and only held the management rights of hotel properties. Hence, these hotel

Table 1. News Articles by Regions and Date of Publications (Pandemic Crisis Stages)

\begin{tabular}{|c|c|c|c|c|}
\hline Region & $\begin{array}{c}\text { Precrisis } \\
\text { Old normal } \\
\text { from December 1, 2019, } \\
\text { to February 29, } 2020\end{array}$ & $\begin{array}{l}\text { Global pandemic } \\
\text { crisis from } \\
\text { March 1, 2020, } \\
\text { to May 31, } 2020\end{array}$ & $\begin{array}{c}\text { Hotel reopen in } \\
\text { new normal conditions } \\
\text { from June } 1,2020 \text {, } \\
\text { to August } 31,2020\end{array}$ & $\begin{array}{l}\text { Learning and } \\
\text { adaptation from } \\
\text { September 1, 2020, } \\
\text { to March 1, } 2021\end{array}$ \\
\hline America & 1 & 52 & 37 & 26 \\
\hline Africa & 0 & 6 & 11 & 3 \\
\hline Asia & 8 & 37 & 26 & 18 \\
\hline Australia & 2 & 12 & 4 & 7 \\
\hline Europe & 1 & 21 & 18 & 22 \\
\hline Total & 12 & 128 & 96 & 76 \\
\hline
\end{tabular}


Figure 1. (Color online) Key Themes Discussed by Global News Media in Pre-Global Crisis Period

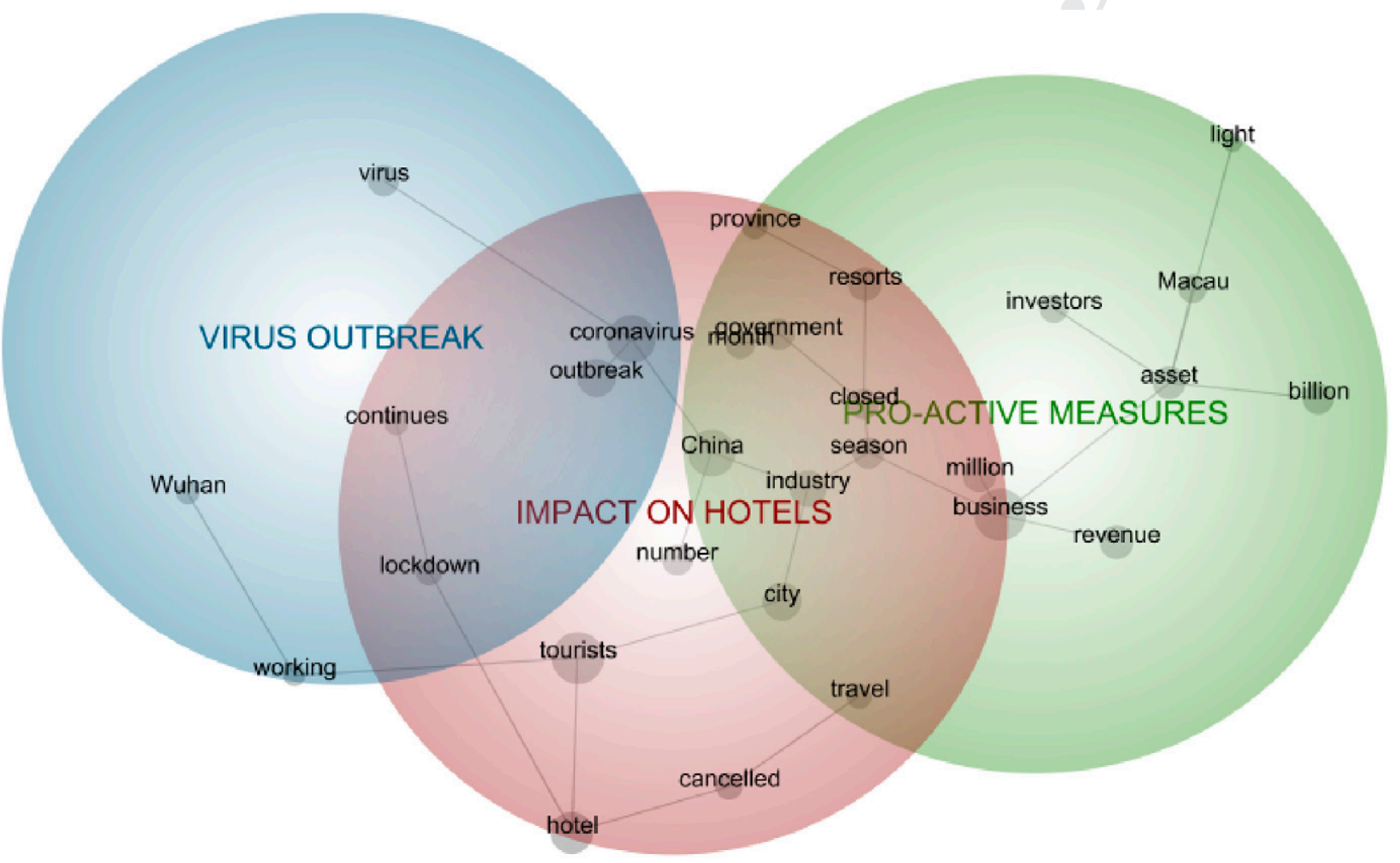

chains were able to quickly build a crisis reserve fund in compensation for the loss of millions of dollars in revenue during the winter holiday season (Macau Daily Times 2020). Other measures identified by manual analysis include suspended new hotel investment projects (Latin Finance 2020) and postponed nonessential renovations to free up working capital (Israeli et al. 2011).

Although some proactive responses were applied by hotel managers, limited attention was paid to the pandemic in this early stage (only 12 news articles recorded). Only when the pandemic became global with a serious outbreak in Europe and the United States did the impacts of the Covid-19 pandemic on the hotel sector and how hotel service providers cope with the pandemic become headlines of most newspapers.

\subsection{Hotels' Reactive Measures at the Global Pandemic Crisis Stage}

Leximancer generated a heat map of four main themes, using 136 news articles between March 1 and May 31: (1) service transformation/diversification (787 occurrences), (2) government regulation and support (744 occurrences), and (3) hotels' corporate social responsibilities (CSR) (183 occurrences). The most important theme identified in news media is service transformation and diversification for hotel survival when the Covid-19 pandemic became global because of a bifurcation event (i.e., increasing numbers of Covid cases in a local community) and the butterfly effect. If the hotels were to remain open, hotel staff must be trained to follow new health and safety guidelines, especially in relation to hygiene (Figure 2). The news media provided warnings for hotels that heavy fines might be applied when new hygiene standards are violated (The Guardian 2020).

When the lockdown measure was applied in many countries (e.g., Spain, France, Germany, etc.), hotel service providers went through a more demanding service transformation process, including becoming quarantine facilities or temporary hospitals for governments (Chaturvedi 2020). Hence, a small portion of selected hotels could generate some revenue to improve their cash flow. However, the majority of hotel businesses had to close operations entirely or only operate minimum services. Given that hotel occupancy was dramatically low, hotel service providers actively diversified their revenue sources through offering new room and food services as well as home delivery services for restaurant products (Figure 2). In addition, some hotels were moving toward business model diversification through offering a mix of short-term 
Figure 2. (Color online) Key Themes Discussed by Global News Media in Global Crisis Period

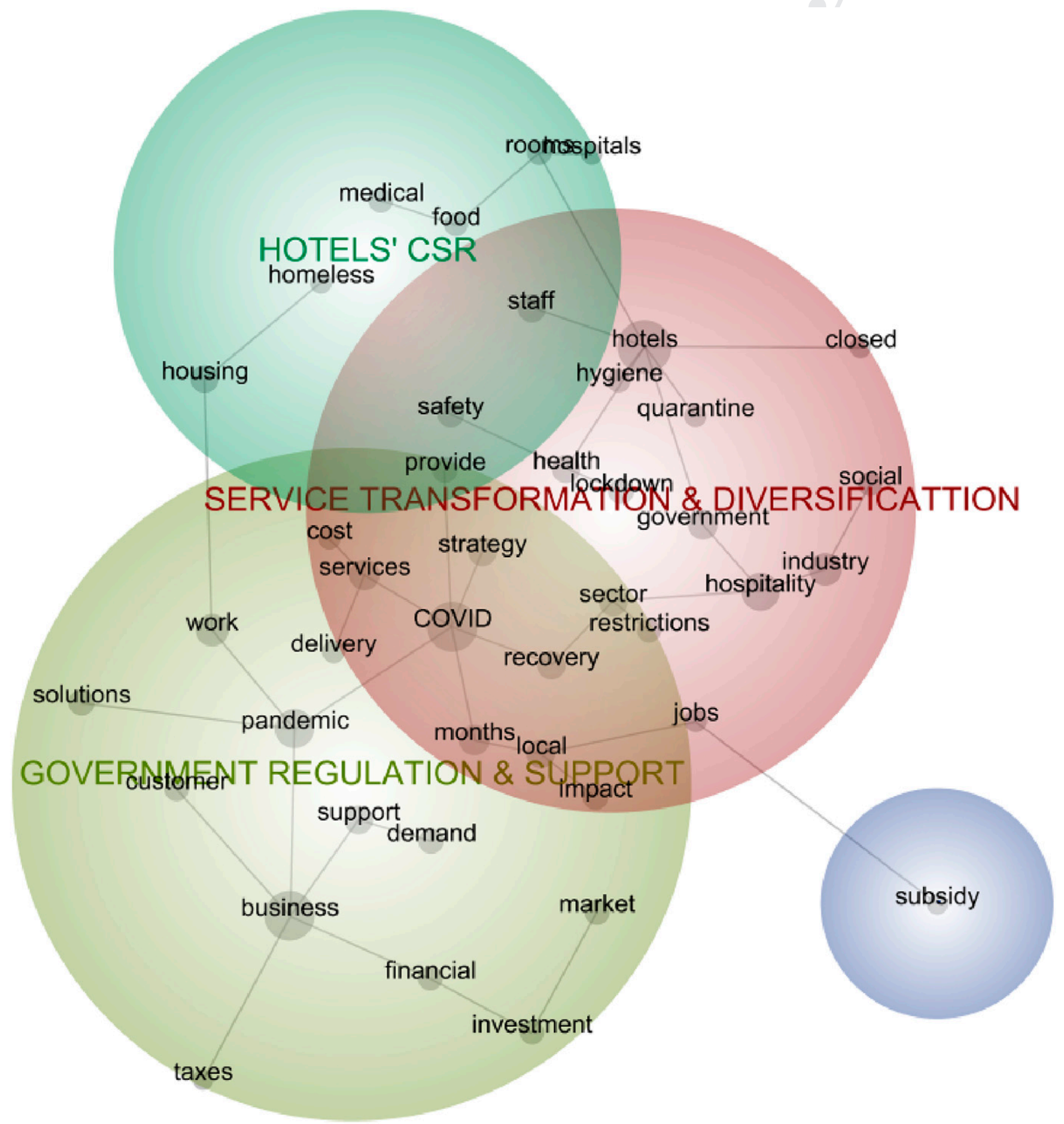

hotel services and medium- to long-term rent contracts to diversify revenue sources (Wynn 2020).

The second theme of government regulations and support reflects the vital role of government in managing the pandemic. Governments in most countries implemented similar regulations to control the virus outbreak from issuing health and safety guidelines to tougher policies, such as lockdown and restrictions on the tourism sector (see Figure 2). Manual analysis revealed policies ranging from travel bans or compulsory quarantine for tourists from certain countries with heavy outbreaks, such as China and Italy, to border closing and lockdown for the entire country. These policies caused direct financial challenges for hotel 
service providers and led to remarkable service transformation/diversification in this sector. The Press Association (2020), for instance, estimates that the hotel sector is facing a cancellation rate of up to $90 \%$ and an occupancy rate under $15 \%$ because of travel bans issued by governments.

Government support such as tax reductions, loans, and/or subsidies was reported by news media as a needed policy to support financial management of the hotel sector in dealing with plummeting demand. However, differences in government support were recorded between developed and developing countries. Governments in developed countries (e.g., the United States, Australia, and New Zealand) launched stimulus packages and offered vital support for the hotel sector (Williams and Price 2020) although hotels in developing countries (e.g., Vietnam, India) received limited support from the government (Vietnamnews 2020). Lobbying for government support is often recommended as a necessary action of hotel businesses to deal with crisis situations (Ritchie 2004). Therefore, cost-cutting measures applied by hotels in this period include reducing staff working hours, increasing unpaid leave and involuntary separation, reducing outsourcing services, and stopping new investment plans. Evidence of these cost-cutting measures could be found in most hotel associations' reports. For example, the Malaysian Association of Hotels surveyed 56,299 hotel employees and found that 2,041 people $(4 \%)$ lost their jobs, $9,773(17 \%)$ were asked to take unpaid leave, and 5,054 (9\%) received pay cuts (Hasandarvish 2020).

Finally, the hotel CSR theme represents creative branding initiatives in the hotel sector in order to build up their good reputation through social responsibility programs; CSR as promotional campaigns were considered inappropriate at the crisis stage. Hotel chains, such as Hilton, Wyndham, and Marriott, provided free social housing for homeless people and for medical staff (Figure 2). These CSR programs were well communicated through news media as effective public relations for these hotel groups.

\subsection{Hotels Reopen in New Normal Conditions}

The Covid-19 pandemic disrupted the development of the hotel sector and marked the flashpoint of change for all hotel service providers (i.e., bifurcation in chaos theory). When most countries move to a new normal—new equilibrium conditions-hotel reopening/ recovery requires further strategic changes. Leximancer generated a heat map of three main themes related to hotel responses in the new normal conditions: (1) service transformation (769 occurrences), (2) business innovation (683 occurrences), and (3) hotel reopening (123 occurrences). Overall, this hotel reopening period marks the self-organization process of the hotel sector through service transformation (i.e., domestic sales and marketing) and business innovation (i.e., digitalization and automation).

The hotel reopening theme includes essential measures applied by hotel service providers to function in new normal conditions. Global news media in this period focused on highlighting the strict applications of new health and safety standards for the guests and staff (see Figure 3). Manual analysis revealed examples of creative solutions, such as accommodating guests' dinners in safe bubbles at the Chester Hotel (Aberdeen, Scotland) (Erskine 2020) or additional training for staff and enhanced cleaning protocols at large hotel chains (e.g., ACCOR hotels) (ACCOR 2020). This reopening period was marked by an improvement in market demand, mostly from local and domestic customers through staycation programs (STR 2020).

Service transformation remains an important theme, representing further changes in hotel services operations from marketing innovation and sales collaboration/strategic partnership to mergers and acquisitions in the hotel sector. First, creative social media marketing campaigns (e.g., virtual room experiences, cooking classes, yoga classes) and promotions through "pay now, party later" discount vouchers/ deals were utilized in European countries and China during the lockdown period (Mulvihill and Beaumont 2020). Massive discounts up to $70 \%$ by many hotel chains (e.g., Wyndham Hotels \& Resorts) provided the opportunity for residents to afford experiential staycations as part of their revenge spending (Dwyer 2020). Alternatively, value-focused sale policies focusing on personalized services and elevated hygiene standards have already been pioneered by several international hotel chains to improve hotel revenue (Hospitalitynet 2020).

Second, news media also reported further sales collaboration and strategic partnerships between hotels and partners. For example, hotels worked closely with online travel agencies (e.g., Booking.com, Expedia) in managing tourist cancellations, promotions, and pricing (Baker 2020). Also, ACCOR formed a strategic partnership with AXA for providing free-of-charge medical service, insurance, and telemedicine solutions for all hotel guests in Australia, New Zealand, and French Polynesia (ACCOR 2020).

Third, the hotel service sector has been restructured by merger and acquisition activities, which also increased. Hotel chain groups, which had firm financial foundations and reserves before/during the pandemic, started to take over hotels with financial difficulties. For example, the number of hotels for sale reached a record high in developing countries, such as Vietnam (Vietnamnet 2020). Also, the InterContinental Hotels Group lost the management rights of 103 
Figure 3. (Color online) Key Themes Discussed by Global News Media in the New Normal Period

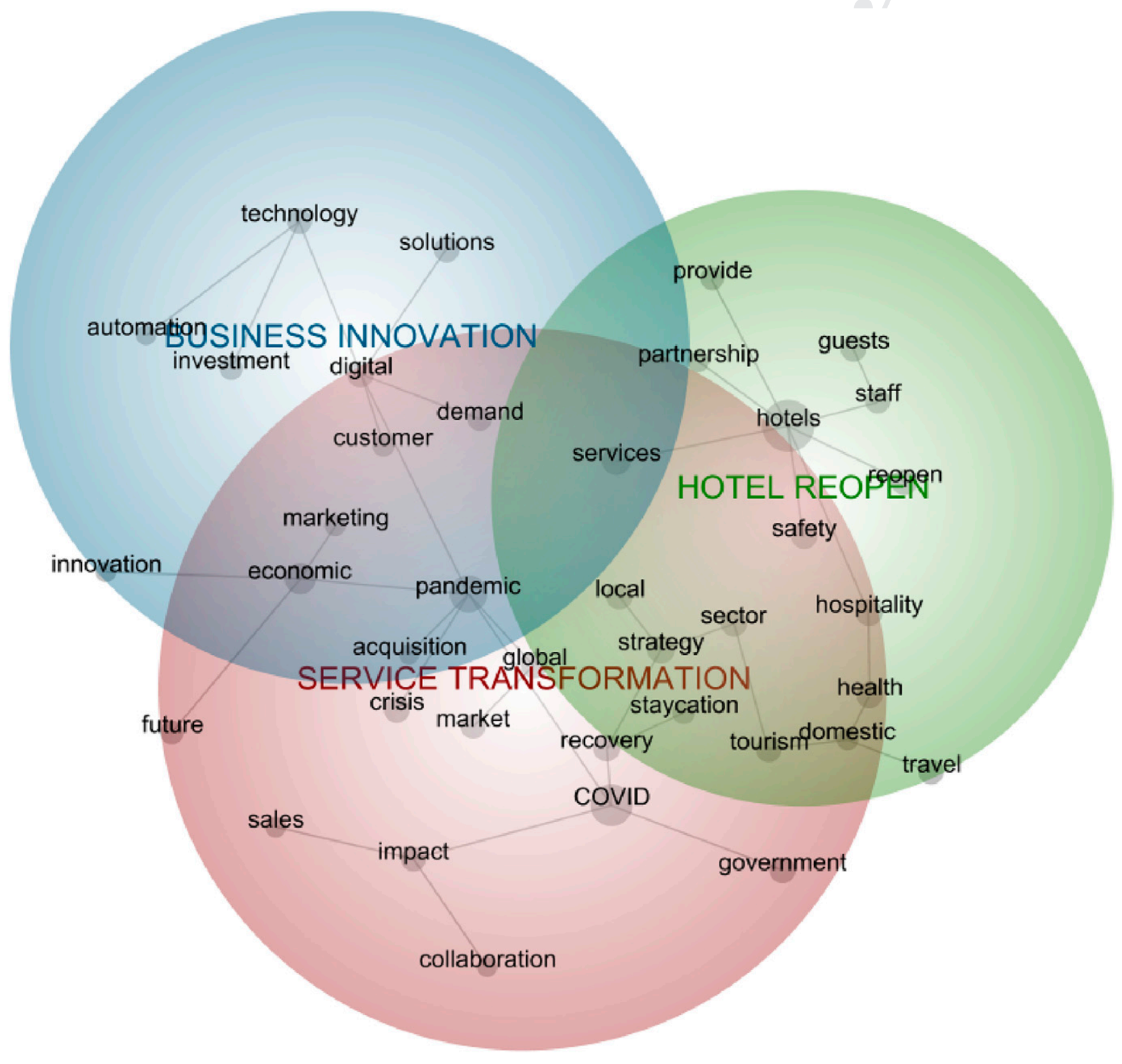

hotels to Sonesta International Hotels Corporation because of its inability to pay minimum returns and rents (Newton 2020). In order to cut operations costs and share knowledge, rumors of a merger between ACCOR Hotels and InterContinental Hotels Group or between Hilton and Hyatt resurfaced (Kwok 2020).

Finally, business innovation emerged as a key theme reflecting the agility and resilience of hotel businesses in dealing with the global pandemic crisis through digital innovations and "automation (Figure 3). Digital solutions and contactless technologies have been widely applied to reduce human contact and, thus, innovate in the labor-intensive hotel sector (Rivera 2020). Hotels have invested in service Q:24 automation, such as mobile concierge apps, to reduce physical interactions and infection risks (Maaty 2020). Q:25 Despite being the future trend of the hotel sector, the adoption of automation is not straightforward and remains constrained by hotel affordance and affordability (Tussyadiah 2020).

\subsection{Hotel Learning and Adaptation in New Travel Context}

Additional data collected from September 1, 2020, to March 1, 2021, provide further insights into the adaptation of the hotel sector when dealing with the 
following waves of the Covid-19 pandemic in many countries. The concept map generated by Leximancer software shows five dominant themes in this period: (1) new travel (with the release of several Covid-19 vaccines, vaccination campaigns in many countries, and the vaccine passport) (860 occurrences), (2) changes in guest behavior (747 occurrences), (3) hotel service transformation (577 occurrences), (4) local tourism (142 occurrences), and (5) digitalization (83 occurrences) (see Figure 4).

This period is marked by new travel forms all over the world as the the Covid-19 pandemic keeps evolving all around the world. Even though some vaccines have been introduced through mass vaccination programs in many countries (e.g., the United States, the European Union, Russia, China), international travel remains challenging because of controversial discussion on a "vaccine passport" (Carter 2021). A quarantine policy remains required by most countries, and applying safety protocols becomes compulsory for all hotel and tourism businesses. In order to open borders and welcome tourists, many tourism destinations (e.g., Cyprus, Spain, Greece, Indonesia) have implemented a process of transformation, protocol, and investment initiatives, such as (1) preparing an action plan to deal with potential emergency situations, (2) formulating an inclusive response to protect vulnerable groups and international protection of tourists, (3) producing a technical assistance package, and (4) raising green awareness (United Nations World Tourism Organization 2021).

In the new travel context, local tourism remains an important customer source for hotels, but there are noticeable changes in guest behavior. Customers are also going to local hotel restaurants for social gathering, using private dining room space when health and safety standards are guaranteed. However, business travelers have been mainly stopped because of workfrom-home policies and online meeting platforms. The most noticeable changing behavior among hotel guests is last-minute buying behavior, which poses big challenges for hotels' short-term planning and revenue management systems. Accommodation reservations are made less than a month before traveling with most domestic travel planning centered on public holidays.

The two themes of service transformation and digitalization continue to play the role of strange attractors that allow hotel businesses to adapt to local tourism trends and changes in guest behavior in the new travel context. Hotels all over the world are now transformed into temporary student housing, longterm rent housing, affordable social housing (taken over by local council) for homeless/at-risk people, or office space (i.e., day office, coworking space). Service transformation trends were initiated in previous periods and are widely spreading in this period as essential opportunities for hotels owners to sell/lease their properties and keep their business afloat in uncertain environments. Also, to address guests' lastminute booking behavior, hoteliers today make their properties bookable up to the last minute as well as introducing extended-stay deals and new pricing strategies. Given that people are presumed not to want to fly much or make long or overseas trips to avoid self-quarantine, there has been emerging regional alliances (e.g., European Tourism Manifesto) that foster local tourism, in which hotels and other tourism operators in nearby destinations work together to create a destination mix to encourage people to spend holidays in nearby regional areas (Lane 2021).

Digitalization has also been accelerated in the hotel sector to avoid human contacts while ensuring customer satisfaction. Digital innovation solutions are applied in various areas, ranging from sending out a personal preference menu prior to the hotel guest arrivals; partnering with wellness technology companies to launch restorative in-room entertainment systems; and enhancing guest well-being through the use of circadian lighting, nonallergenic materials, and improved air quality. Furthermore, advanced services, such as automated check-in and -out processes based on keyless entry systems, have been considered as new service norms at hotels in addition to digital tour guides utilizing global positioning system technologies as well as tourist attraction recommendation systems, which are being applied to the hospitality sector.

\section{Discussion and Practical Implications}

A significant global crisis such as the Covid-19 pandemic has transformed the hotel sector and requires hotels to adapt their service operations and structures in the new travel age. Using global news media, this paper analyzes hotels' responses to the pandemic via a life-cycle crisis management framework (Mitroff and Pearson 1993, Faulkner 2001) from a chaotic Q:26 perspective (McKercher 1999, Zahra and Ryan 2007, Olmedo and Mateos 2015) and learning/adaptation approach. Based on findings discussed in the previous section, a refined pandemic crisis management model is proposed (see Figure 5). In addition to three main stages (precrisis, crisis, hotel reopen or short recovery) as proposed in the existing literature, the learning and adaptation stage is added to the framework to reflect the original nature of the Covid-19 pandemic. Although the second, third, or even forth waves of the Covid-19 outbreak are ongoing in many countries, the hotel sector needs to continuously learn and adapt to the new travel age. Various reactive, proactive, and resilience strategies applied by hoteliers to deal with the 
Figure 4. (Color online) Key Themes Discussed by Global News Media in the New Travel Period

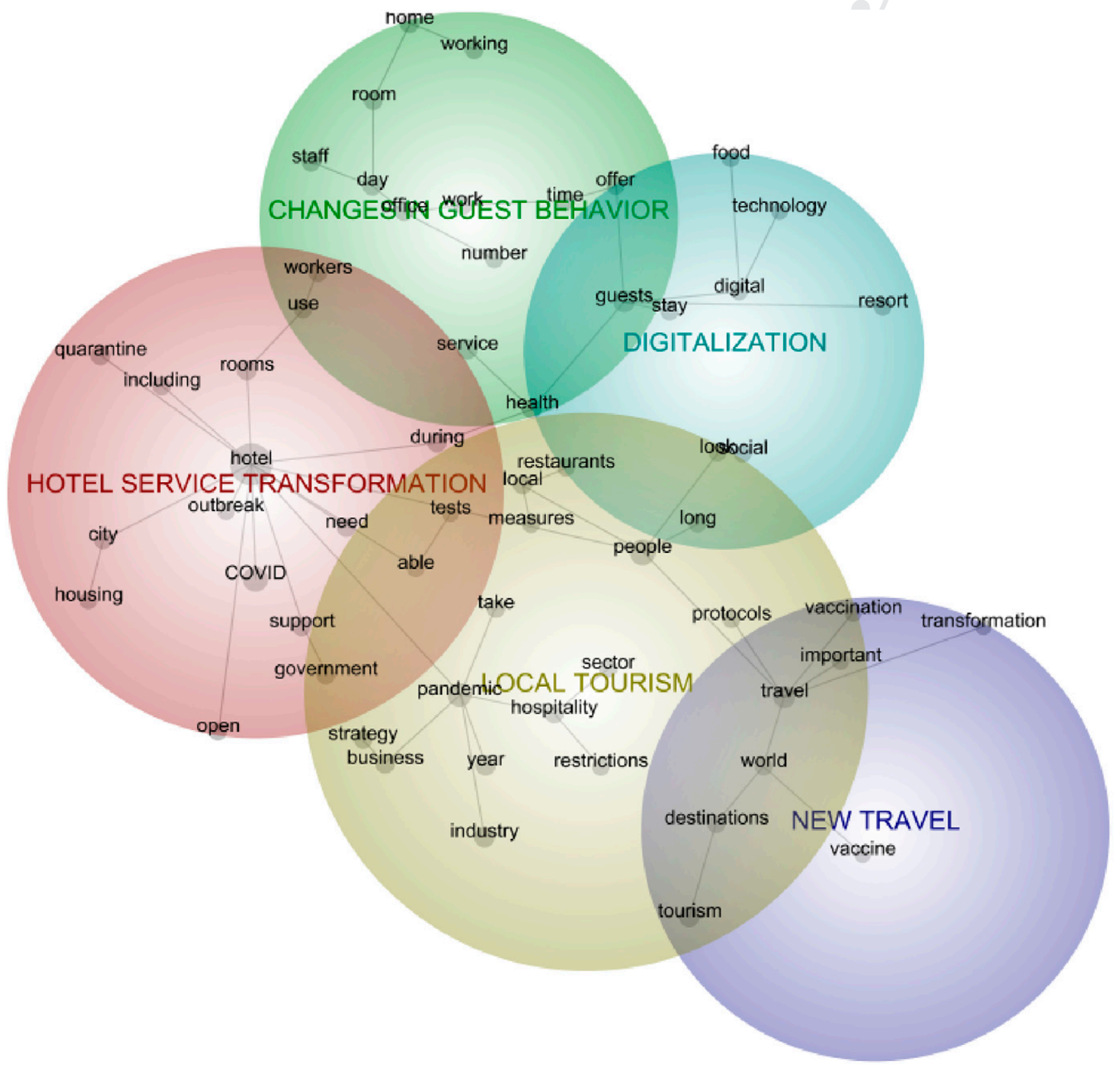

unprecedented global Covid-19 pandemic crisis are identified and associated with each stage of the pandemic. Further discussion on lessons learned for the hotel sector is provided as follows.

\subsection{Crisis-Readiness Proactive Strategy in the Precrisis Stage}

Based on a chaotic perspective and behavioral learning theory, this study suggests that a crisis-readiness proactive strategy is critical for hotel service providers to be prepared for chaotic and complex environments, which should complement crisis planning. Instead of trying to forecast unpredictable crises, the development and application of effective signal detection can be the first line of defense in crisis management (Paraskevas and Altinay 2013). Based on scenario analysis, hotel businesses should proactively save financial resources, prepare human resources, and adopt technological resources to effectively manage emergency and crisis stages. As demonstrated in this study, only a limited number of hotel chains (e.g., MGM China or Lemon Tree Hotels) were found to implement these proactive crisis-readiness initiatives. Crisis planning can still work in dealing with repeatable events (e.g., 
Figure 5. (Color online) A Strategic Pandemic Crisis Management Framework for Hotel Service Providers

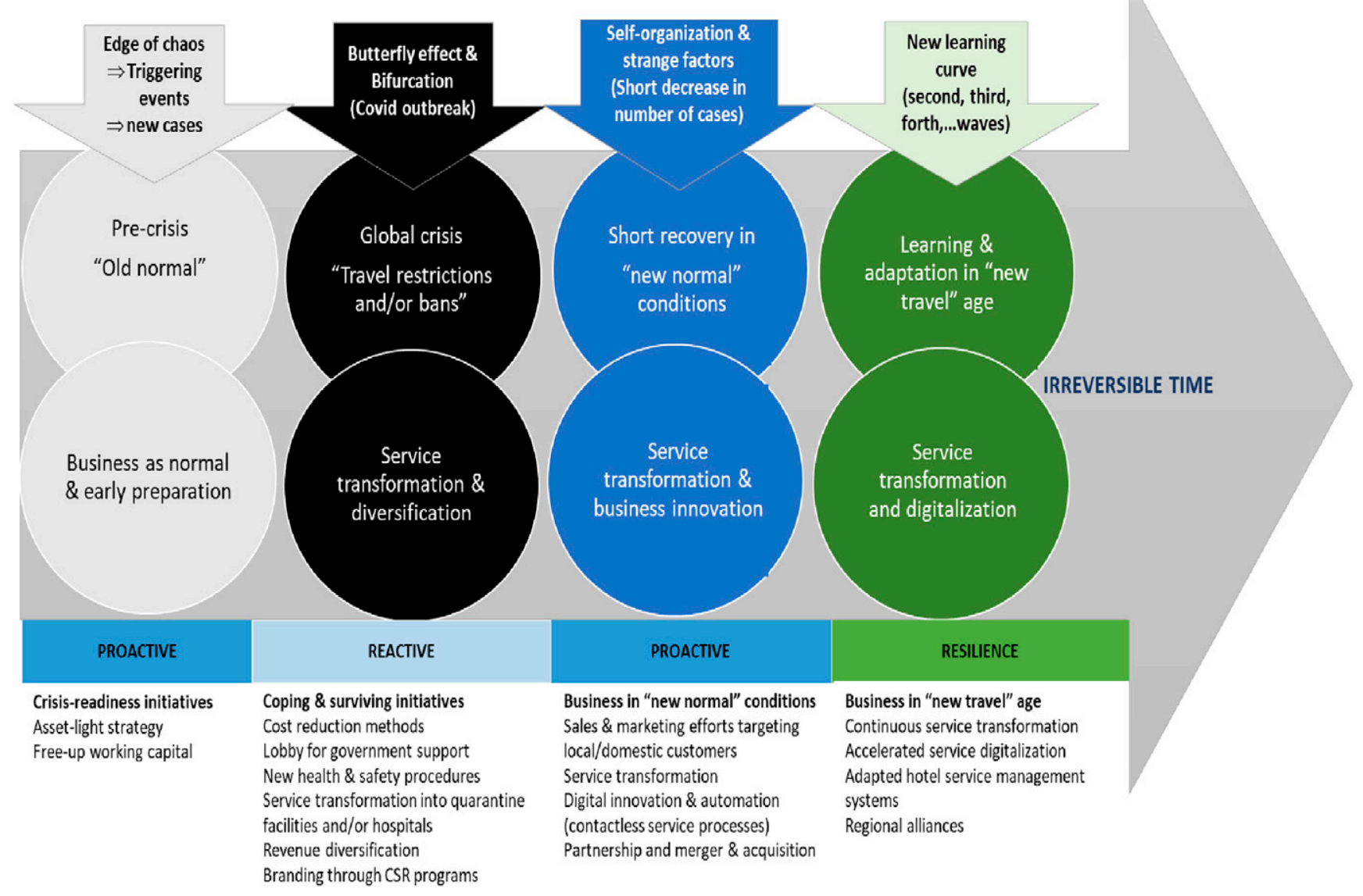

second or third waves of the Covid outbreak), which allows hotels to learn from the past and adapt to new conditions. However, no matter how comprehensive and robust crisis and disaster management plans are, these plans are not enough to mitigate the impact of evolving, changing, and unpredictable events, such as Hurricanes Katrina and Irma (Prayag 2018) and this Covid-19 pandemic (Gössling et al. 2020). Hotels need to continuously learn and adapt to changing environments through utilizing strange attractors (e.g., service transformation and digitalization).

\subsection{Reactive Strategies for Hotel Survival in a Global Pandemic Crisis}

A wide range of coping and surviving strategies employed by the hotel sector are identified. Some of these reactive strategies are not unique to the Covid19 crisis but have found great support in the past literature. For instance, similar cost-cutting measures were implemented by hotel services providers as a necessary crisis/disaster response for decades (Wang and Ritchie 2011), including reducing operation costs (e.g., labor cost) (Leung and Lam 2004), improving operation efficiency (Naidoo 2010), and cutting outsourcing services (Kim et al. 2005). The hibernation strategy was crucial for hotels that possess limited financial resources to temporarily close and save resources for reopening in the next stage. Given that marketing activities in crisis situations could be deemed insensitive and inappropriate (Page et al. 2006), most hotels have maintained their visibility and reputation in global crisis through implementing CSR initiatives, which is consistent with previous research (Kucukusta et al. 2013).

\subsection{Utilizing Strange Attractors as Part of Proactive and Resilience Strategies in Changing Environments}

Creative solutions, such as service transformation, digitalization, and partnerships/alliances (i.e., strange attractors), initiated by some hotels in the global crisis and hotel reopening stages have been quickly adopted by others as part of the self-organization process of the whole tourism and hospitality system in the learning/ adaptation stage. These strange attractors allow hoteliers to proactively function in new normal conditions 
and strengthen their resilience in the changing new travel age (see Figure 5).

First, hotels rely on service transformation to deal with fundamental changes in the economic system (which may be positive or negative) (Scott and Laws 2006). The hotel sector has been functioning in similar ways since its beginning, mainly focusing on shortterm accommodation and food and beverage services to serve travelers from long distances. This pandemic is forcing hotel service providers to make significant service transformations and redefine the shape of the hotel sector in the 21st century. Hotels are temporarily transformed for dynamic using purposes from longterm housing or temporary work space to social/ entertainment places for local residents and people living in neighborhood areas. This service transformation may lead to permanent changes in hotel functions and services in the following years, allowing hotels to accommodate various needs of local, regional, and international travelers.

Second, the digitalization process, initially applied by some hotels during crisis situations, has become an essential strategy for hotels (see Figures 3-5). Our study emphasizes findings of previous studies on the importance of digital innovation in improving hotel performance (Enz and Way 2016), suggesting that technology-based service innovation can be part of an effective crisis management strategy. Following previous research that demonstrates how technologyenabled services (e.g., tabletop technology, digital service inventories) can enhance service delivery and customer value (Davis et al. 2015, Lee et al. 2015, Susskind and Curry 2016), current research shows that the integration of automated and contactless technologies into hotel service delivery processes have become common practices for public safety reasons after the Covid-19 pandemic. Following technological adoption, organizational changes and/or restructuring must be implemented (Wang and Ritchie 2010). Hotels may need to apply necessary processes and deliverables to develop and disseminate technologyassisted service systems (Watanabe and Mochimaru 2017).

Third, our findings suggest that the global pandemic produces an altered trend path that leads to a more cohesive industry, wide response mechanisms, and critical organizational restructures (Quarantelli 1988). There is considerable evidence of merger and acquisition trends and collaborative strategy through regional partnerships/alliances between hotels and other tourism/hospitality organizations (e.g., tour operators, online travel agencies, airlines, destination management organizations) in the hotel reopening and learning/adaptation stages. The importance of stakeholder collaboration in rescuing the hotel sector in chaotic and complex pandemic crisis situations is highlighted in accordance with suggestions of many academics (Ritchie 2009, Speakman and Sharpley 2012). Therefore, crises force stakeholder collaboration in resource management to form a more efficient structure and business network in postcrisis situations (Aliperti et al. 2019), achieving a new system balance after completing the self-organization process.

\subsection{Importance of Learning and Adaptation in Pandemic Crisis Management}

The adaptability of hotel businesses to chaos and crises, thus, also depends on the knowledge retained from past events, which can be considered as a portfolio of risk management. This study demonstrates how crisis management from a chaos perspective can be incorporated with behavioral learning theory (Skinner 1965, Rothschild and Gaidis 1981), in which organizational behaviors are learned through interactions with the environment. Businesses are stimulated to learn as they go from the past and current crisis events and adapt to evolving situations with more simultaneous and proactive responses (Haleblian and Finkelstein 1999). The learning/adaptation stage is critical in the proposed crisis management framework because the pandemic remains constantly changing (i.e., Covid-19 with various mutant strains with accelerated infection rates and governments' rapid reactions in relation to travel/service operation policies) (see Figure 5). For instance, learning as adaptation has resonated through the widely adopted service transformation process of hotel properties into temporary student housing, long-term rent housing, and affordable social housing, even work space, to accommodate current needs/demands of local customers (see Figure 4).

Furthermore, hotel learning and adaptation have echoed through important adjustments in hotel shortterm planning and revenue management systems in response to changing travel behavior as well as adoption of digital innovation solutions to reduce customers' risk perceptions and to ensure the optimum service efficiency (Le and Arcodia 2018). Hence, it is increasingly imperative for hotel businesses to strengthen knowledge management and learning culture in order to become more resilient during the continuous and evolving pandemic.

\section{Conclusion}

A significant global crisis such as the Covid-19 pandemic raises general issues of how hotel service providers learn and adapt to chaotic and complex environments. This paper set out to analyze how hotel businesses respond, innovate, and transform throughout different stages of the pandemic as observed and reported by global news media. Our theoretical contribution is through proposing a pandemic crisis 
management framework based on a chaotic perspective and learning approach for hotel service providers to reassess the current Covid-19 pandemic and adapt to the new travel age. The paper also contributes to the broader service science literature in the areas of service operations and innovations by identifying hotels' reactive, proactive, and resilience strategies so far (see Figure 5).

Instead of crisis management planning, our paper demonstrates how adopting a chaotic perspective and early crisis-signal system enable hotel managers to be proactively ready for crisis situations. Crisis establishes a breeding ground for service innovation and transformation. Instead of taking the victim role in a crisis, hotel businesses can seize the transformation/ innovation opportunities in crisis situations and strategically adapt to changing environments to secure a strong competitive advantage.

Besides its contributions, this paper is subject to several limitations. First, the search and inclusion of
English news media only may lead to the exclusion of relevant and useful information from non-English sources. Future research may expand the database with non-English news articles to provide a more comprehensive understanding of hotels' strategic responses to the Covid-19 pandemic. Second, case-study investigation in each classification of hotels (e.g., hotel chains versus local/small hotel business) will provide in-depth analysis of appropriate strategies in accordance with hotel size and resources. Third, this study reveals that hotels rely largely on government support and strategic collaboration/alliance with other stakeholders to survive in pandemic situations. Therefore, more studies are needed to explore the influences of governance and stakeholder dynamics in hotel pandemic crisis management. Finally, it is also important to investigate further the influences of effective knowledge management and learning culture in service businesses on crisis management performance.

Appendix. Key Concepts per Theme Included in the Leximancer Figures

\begin{tabular}{|c|c|c|c|}
\hline $\begin{array}{l}\text { Figure } 1 \\
\text { Pre-global crisis period }\end{array}$ & $\begin{array}{c}\text { Figure } 2 \\
\text { Global pandemic crisis }\end{array}$ & $\begin{array}{c}\text { Figure } 3 \\
\text { New normal }\end{array}$ & $\begin{array}{c}\text { Figure } 4 \\
\text { New travel }\end{array}$ \\
\hline $\begin{array}{l}\text { Virus outbreak } \\
\text { Virus } \\
\text { Wuhan } \\
\text { Continue } \\
\text { Coronavirus } \\
\text { Outbreak } \\
\text { Lockdown } \\
\text { Working }\end{array}$ & $\begin{array}{l}\text { Government regulations } \\
\text { and support } \\
\text { Business } \\
\text { Support } \\
\text { Demand } \\
\text { Financial } \\
\text { Investment } \\
\text { Market } \\
\text { Taxes } \\
\text { Customer } \\
\text { Solutions } \\
\text { Pandemic } \\
\text { Local } \\
\text { Impact } \\
\text { Jobs } \\
\text { Subsidy }\end{array}$ & $\begin{array}{l}\text { Hotel reopening } \\
\text { Hotels } \\
\text { Reopen } \\
\text { Staff } \\
\text { Guests } \\
\text { Safety } \\
\text { Partnership } \\
\text { Local } \\
\text { Tourism } \\
\text { Strategy } \\
\text { Staycation } \\
\text { Domestic } \\
\text { Travel } \\
\text { Health } \\
\text { Provide }\end{array}$ & $\begin{array}{l}\text { New travel } \\
\text { World } \\
\text { Travel } \\
\text { Important } \\
\text { Vaccination } \\
\text { Transformation } \\
\text { Destinations } \\
\text { Tourism }\end{array}$ \\
\hline $\begin{array}{l}\text { Impact on hotel } \\
\text { Industry } \\
\text { Tourists } \\
\text { City } \\
\text { Season } \\
\text { Closed } \\
\text { Hotel } \\
\text { Resorts } \\
\text { Travel } \\
\text { Cancelled } \\
\text { Government } \\
\text { Lockdown } \\
\text { Millions }\end{array}$ & $\begin{array}{l}\text { Service transformation and } \\
\text { diversification } \\
\text { Hotels } \\
\text { Closed } \\
\text { Staff } \\
\text { Hygiene } \\
\text { Quarantine } \\
\text { Health } \\
\text { Safety } \\
\text { Lockdown } \\
\text { Government } \\
\text { Hospitality sector / industry } \\
\text { Social } \\
\text { Covid }\end{array}$ & $\begin{array}{l}\text { Service transformation } \\
\text { Economic } \\
\text { Marketing } \\
\text { Future } \\
\text { Pandemic } \\
\text { Acquisition } \\
\text { Global } \\
\text { Market } \\
\text { Covid } \\
\text { Recovery } \\
\text { Government } \\
\text { Impact } \\
\text { Sales } \\
\text { Collaboration }\end{array}$ & $\begin{array}{l}\text { Hotel service } \\
\text { transformation } \\
\text { Quarantine } \\
\text { Hotel } \\
\text { Rooms } \\
\text { During } \\
\text { Tests } \\
\text { Covid } \\
\text { Outbreak } \\
\text { Government } \\
\text { Support } \\
\text { City } \\
\text { Housing } \\
\text { Open }\end{array}$ \\
\hline
\end{tabular}


Appendix. (Continued)

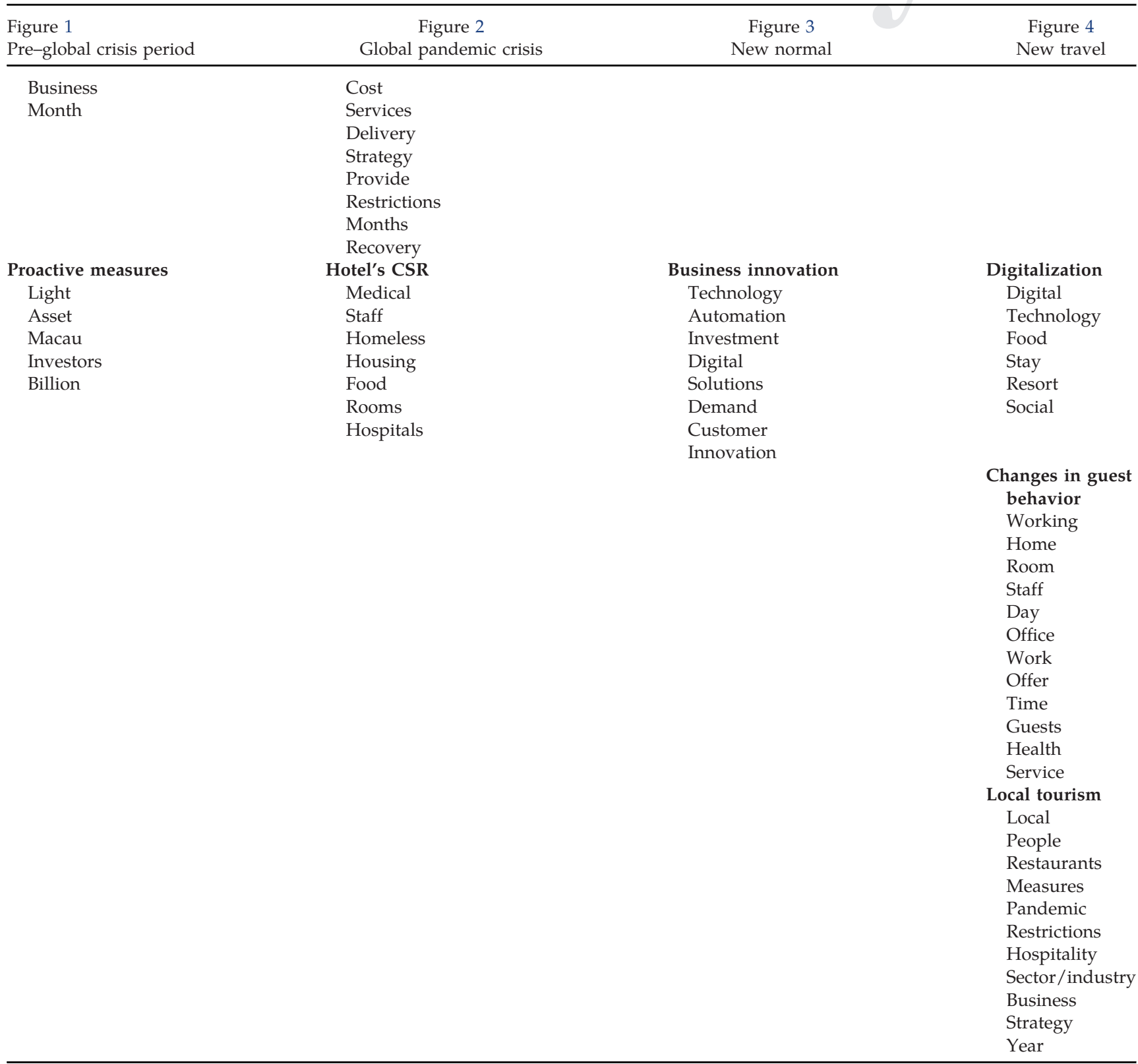

Note. Leximancer allows researchers to explore the relationship between key concepts and find relevant quotes from the textual data (see following examples, Figure A.1). 
Figure A.1. (Color online)

Welcome Project Control: Pre-crisis $\times 80$ Map Explorer: Pre-crisis $x$ Project Control: Global crisis $x$

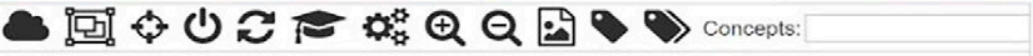

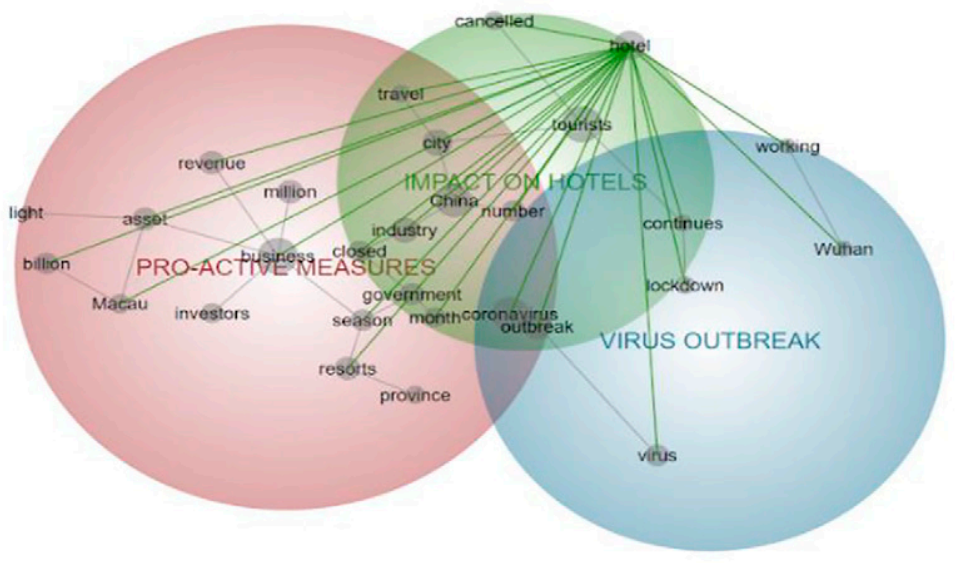

Visible Concepts: $100 \%$

Theme Size: $\mathbf{6 5} \%$

Rotation: $\mathbf{2 2 7}$

4 lorer: Global crisis $x$ \&o Map Explorer: Global crisis $x$ Project Control: Hotel recovery $x$ So Map Explorer: Hotel recovery $x$ So Map Explorer: Hotel recovery $\times$

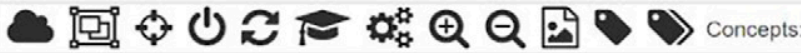

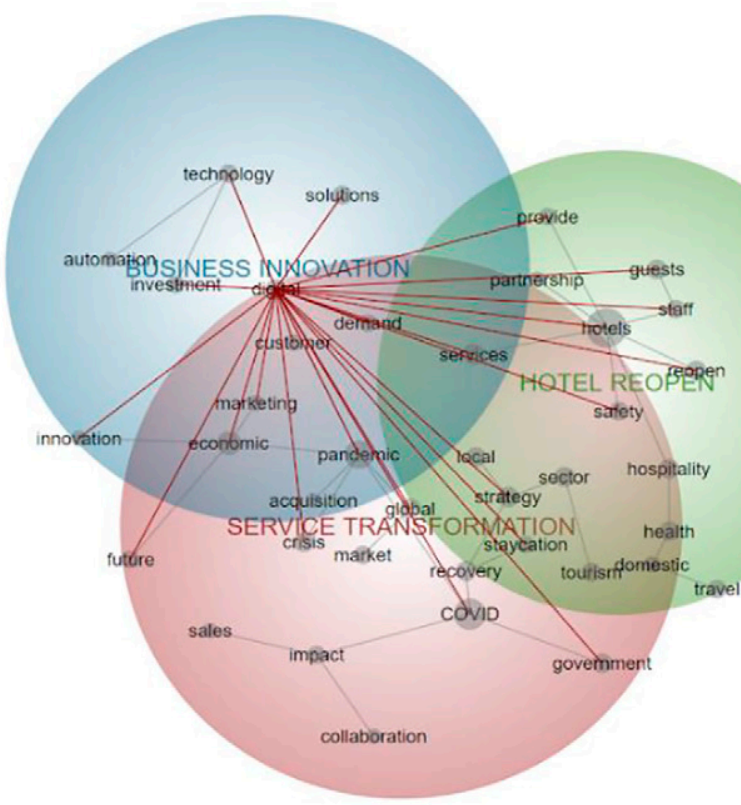

Q custome

Q technology

Q solutions

Q demand

Q future

Q services

Q innovation

Q marketing

a pandemic

Q economic

Q staycation

Q staff

Q crisis

Q safety

Q provide

Q global

Q hotels

Q guests

Q strategy

Q government

$\mathbf{Q}$ investment

Q reopen
4 Synopsis Concepts Thesaurus Query Summ WORD:tourists WORD:coronavirus NAME:China WC Search

Export Page Export All LogAll

Result

Tashi Namgay Resort, a popular three-star hotel is experiencing cancellation every day from both local and foreign agents.

Resort employees said many Chinese tourists had

already cancelled their bookings and tourists from

Europe and India are also now cancelling bookings.

11 Dec to 29 Feb.DOCX/1 Dec to 29 Feb 1.html 142 Add to $\log$ Concepts

Australians are being warned against travelling to China due to coronavirus

Home Affairs Minister Peter Dutton said people were still travelling to China

He warned the government could not guarantee safe return if borders closed

Scott Morrison says people should not assume more evacuation flights possible

Australians are being warned against travelling to

China as coronavirus continues to spread and take

more lives.

Home Affairs Minister Peter Dutton said people were still travelling from Australia to China in defiance of official advice.

I4 $|+|>D \mid$ Displaying results $1-10$ of 92




\section{References}

ACCOR (2020) Accor healthcare partnership with AXA goes live. https://www.hospitalitynet.org/news/4100234.html.

Aliperti G, Sandholz S, Hagenlocher M, Rizzi F, Frey M, Garschagen M (2019) Tourism, Crisis, Disaster: An Interdisciplinary Approach. Ann. Tourism Res. 79:102808.

Baggio R (2008) Symptoms of complexity in a tourism system. Tourism Anal. 13(1):1-20.

Baker T (2020) UK hoteliers rethink relationships with 'silent' OTAs. https://www.hotelnewsnow.com/Articles/304104/UK-hoteliers -rethink-relationships-with-silent-OTAs.

Carter S (2021) International travel won't rely on fancy vaccine passports. https://www.bloomberg.com/opinion/articles/2021-0410/international-travel-won-t-rely-on-vaccine-passports-or-qrcodes?utm_source $=$ google\&utm_medium $=$ cpc\&utm_campaign $=$ dsa\&utm_term $=\&$ gclid=Cj0KCQjwytOEBhD5ARIsANnRjViN tvLitcYA_Gn7zkTILNRCSBOpeaAslfvAJuat1FyXuAI9NipNp UoaAkNyEALw_wcB.

Chaturvedi A (2020) Hoteliers, industry bodies express concerns about more hotels being requisitioned by Delhi government. https://economictimes.indiatimes.com/industry/services/hotels -/-restaurants/hoteliers-industry-bodies-express-concerns-about -more-hotels-being-requisitioned-by-delhi-government/article show /76409693.cms?utm_source=contentofinterest\&utm_ medium=text\&utm_campaign $=$ cppst.

Cohen E, Neal M (2010) Coinciding crises and tourism in contemporary Thailand. Current Issues Tourism 13(5):455-475.

Cooper M (2006) Japanese tourism and the SARS epidemic of 2003. J. Travel Tourism Marketing 19(2-3):117-131.

Dwyer C (2020) Luxury hotels in Asia offering stellar deals for travelers amid coronavirus. https://edition.cnn.com/travel/article/ asia-hotel-deals-covid-19/index.html.

Erskine R (2020) Scottish hotel to install "eden project" style domes for alfresco dining-Here's how it'll work. https://foodanddrink. scotsman.com/in-the-news/scottish-hotel-to-install-eden-projectstyle-domes-for-alfresco-dining-heres-how-itll-work/.

Faulkner B (2001) Toward a framework for tourism disaster management. Tourism Management 22(2):135-147.

Felsenthal M (2020) COVID-19 to plunge global economy into worst recession since World War II.

Fink S (1986) Crisis Management: Planning for the Inevitable (American Management Association, New York).

Ghaderi Z, Mat Som AP, Wang J (2014) Organizational learning in tourism crisis management: An experience from Malaysia. J. Travel Tourism Marketing 31(5):627-648.

Gössling S, Scott D, Hall CM (2020) Pandemics, tourism and global change: A rapid assessment of COVID-19. J. Sustainable Tourism 29(1):1-20.

The Guardian Online (2020) Australia's civil liberties under coronavirus. (March 26), https://www.theguardian.com/world/2020/ mar/26/australias-civil-liberties-under-coronavirus-advocateswarn-laws-must-be-temporary.

Guney A, Al S (2012) Effective learning environments in relation to different learning theories. Procedia Soc. Behav. Sci. 46:2334-2338.

Haleblian J, Finkelstein S (1999) The influence of organizational acquisition experience on acquisition performance: A behavioral learning perspective. Admin. Sci. Quart. 44(1):29-56.

Hao F, Xiao Q, Chon K (2020) COVID-19 and China's hotel industry: Impacts, a disaster management framework, and post-pandemic agenda. Internat. J. Hospitality Management 90: 102636.

Hasandarvish M (2020) Covid-19: Malaysia's hotels draw up new strategies in view of RM3.3b in losses forcing thousands out of job, says association. https://www.malaymail.com/news/life/ 2020/04/17/covid-19-malaysias-hotels-draw-up-new-strategiesin-view-of-rm3.3b-in-losse/1857655.
Henderson J, Ng A (2004) Responding to crisis: Severe acute respiratory syndrome (SARS) and hotels in Singapore. Internat. J. Tourism Res. 6(6):411-419.

Huang Y-C, Tseng Y-P, Petrick JF (2008) Crisis management planning to restore tourism after disasters: A case study from Taiwan. J. Travel Tourism Marketing 23(2-4):203-221.

Jayawardena C, Tew PJ, Lu Z, Tolomiczenko G, Gellatly J (2008) SARS: Lessons in strategic planning for hoteliers and destination marketers. Internat. J. Contemporary Hospitality Management 20(3):332-346.

Kim SS, Chun H, Lee H (2005) The effects of SARS on the Korean hotel industry and measures to overcome the crisis: A case study of six Korean five-star hotels. Asia Pacific J. Tourism Res. 10(4):369-377.

Kubickova M, Kirimhan D, Li H (2019) The impact of crises on hotel rooms' demand in developing economies: The case of terrorist attacks of 9/11 and the global financial crisis of 2008. J. Hospitality Tourism Management 38:27-38.

Kwok L (2020) Will COVID-19 be a catalyst for more hotel mergers and acquisitions? https://www.hospitalitynet.org/opinion/ 4100587.html.

Lane M (2021) Europe travel and tourism alliance urges regional plan to restore freedom of movement by Summer. https:// www.moodiedavittreport.com/ europe-travel-and-tourismalliance-urges-regional-plan-to-restore-freedom-of-movementby-summer/.

Le D, Phi G (2021) Strategic responses of the hotel sector to COVID19: Toward a refined pandemic crisis management framework. Internat. J. Hospitality Management 94:102808.

Le D, Scott N, Becken S, Connolly R (2019) Tourists' aesthetic assessment of environmental changes, linking conservation planning to sustainable tourism development. J. Sustainable Tourism 27 (10):1477-1494.

Le TH, Arcodia C (2018) Risk perceptions on cruise ships among young people: Concepts, approaches and directions. Internat. J. Hospitality Management 69:102-112.

Leung P, Lam T (2004) Crisis management during the SARS threat: A case study of the metropole hotel in Hong Kong. J. Human Resources Hospitality Tourism 3(1):47-57.

Levy D (1994) Chaos theory and strategy: Theory, application, and managerial implications. Strategic Management J. 15(S2):167-178.

Lo A, Cheung C, Law R (2006) The survival of hotels during disaster: A case study of Hong Kong in 2003. Asia Pacific J. Tourism Res. 11(1):65-80.

Lorenz EN (1995) The Essence of Chaos (University of Washington Press, Seattle, WA).

Maphanga PM, Henama US (2019) The tourism impact of Ebola in Africa: Lessons on crisis management. African J. Hospitality Tourism Leisure 8(3):1-13.

McKercher B (1999) A chaos approach to tourism. Tourism Management 20(4):425-434.

Moe TL, Pathranarakul P (2006) An integrated approach to natural disaster management. Disaster Prevention Management Internat. J. 15(3):396-413.

Murphy P (1996) Chaos theory as a model for managing issues and crises. Public Relations Rev. 22(2):95-113.

Naidoo V (2010) Firm survival through a crisis: The influence of market orientation, marketing innovation and business strategy. Indust. Marketing Management 39(8):1311-1320.

Newton M (2020) Service properties trust to transfer 103 hotels to Sonesta from IHG. https://www.hospitalitynet.org/news/ 4100335.html.

Novelli M, Burgess LG, Jones A, Ritchie BW (2018) "No Ebola ... still doomed"-The Ebola-induced tourism crisis. Ann. Tourism Res. 70:76-87.

Olmedo E, Mateos R (2015) Quantitative characterization of chaordic tourist destination. Tourism Management 47:115-126. 
Oppermann M (2000) Tourism destination loyalty. J. Travel Res. 39 (1):78-84.

Page S, Song H, Wu DC (2012) Assessing the impacts of the global economic crisis and swine flu on inbound tourism demand in the United Kingdom. J. Travel Res. 51(2):142-153.

Page S, Yeoman I, Munro C, Connell J, Walker L (2006) A case study of best practice-Visit Scotland's prepared response to an influenza pandemic. Tourism Management 27(3):361-393.

Pappas N (2018) Hotel decision-making during multiple crises: A chaordic perspective. Tourism Management 68:450-464.

Paraskevas A (2006) Crisis management or crisis response system? A complexity science approach to organizational crises. Management Decision 44(7):892-907.

Pauchant T, Mitroff I (1992) Transforming the Crisis-Prone Organization: Preventing Individual, Organizational, and Environmental Tragedies (Jossey-Bass, San Francisco).

Pearson CM, Mitroff II (1993) From crisis prone to crisis prepared: A framework for crisis management. Acad. Management Perspect. 7(1):48-59.

Pforr C, Hosie PJ (2008) Crisis management in tourism. J. Travel Tourism Marketing 23(2-4):249-264.

Phi GT (2019) Framing overtourism: A critical news media analysis. Current Issues Tourism 23(17):2093-2097.

Prayag G (2018) Symbiotic relationship or not? Understanding resilience and crisis management in tourism. Tourism Management Perspect. 25:133-135.

Preble J (1993) Crisis management of financial institutions. Amer. Bus. Rev. 11(1):72-79.

Quarantelli EL (1988) Disaster crisis management: A summary of research findings. J. Management Stud. 25(4):373-385.

Ritchie B (2004) Chaos, crises and disasters: A strategic approach to crisis management in the tourism industry. Tourism Management 25(6):669-683.

Ritchie BW (2009) Crisis and Disaster Management for Tourism (Channel View Publications, Australia).

Ritchie B, Jiang Y (2019) A review of research on tourism risk, crisis and disaster management: Launching the annals of tourism research curated collection on tourism risk, crisis and disaster management. Ann. Tourism Res. 79:102812.

Rothschild ML, Gaidis WC (1981) Behavioral learning theory: Its relevance to marketing and promotions. J. Marketing 45(2):70-78.

Saunier RE, Meganck RA (2004) CHAOSS: Glossary of Environmental Governance (CRC Press).

Schweinsberg S, Darcy S, Cheng M (2017) The agenda setting power of news media in framing the future role of tourism in protected areas. Tourism Management 62:241-252.
Scott N, Laws E (2006) Tourism crises and disasters: Enhancing understanding of system effects. J. Travel Tourism Marketing 19 (2-3):149-158.

Scott N, Laws E, Prideaux B (2008) Tourism crises and marketing recovery strategies. J. Travel Tourism Marketing 23(2-4):1-13.

Sellnow TL, Seeger MW, Ulmer RR (2002) Chaos theory, informational needs, and natural disasters. J. Appl. Comm. Res. 30(4): 269-292.

Skinner BF (1965) Science and Human Behavior (Simon and Schuster).

Speakman M, Sharpley R (2012) A chaos theory perspective on destination crisis management: Evidence from Mexico. J. Destination Marketing Management 1(1):67-77.

Thietart R-A, Forgues B (1995) Chaos theory and organization. Organ. Sci. 6(1):19-31.

Tussyadiah I (2020) Automating hospitality in times of social distancing. Accessed July 25, 2020, https://www.hospitalitynet. org/opinion/4097965.html.

United Nations World Tourism Organization (2021) Tourism takes steps to reopen. https://www.unwto.org/restarting-tourism.

Vietnamnet (2020) Number of hotels on sale reaches record in Vietnam. https://vietnamnet.vn/en/business/number-of-hotels-onsale-reaches-record-in-vietnam-674132.html.

Wang J, Ritchie BW (2011) A theoretical model for strategic crisis planning: Factors influencing crisis planning in the hotel industry. Internat. J. Tourism Policy 3(4):297-317.

Whitten D, Chakrabarty S, Wakefield R (2010) The strategic choice to continue outsourcing, switch vendors, or backsource: Do switching costs matter? Inform. Management 47(3):167-175.

Wilks J, Moore S (2004). Tourism Risk Management for the Asia Pacific Region: An Authoritative Guide for Managing Crises and Disaster$s: A$ Report (APEC International Centre for Sustainable Tourism, Australia).

Yang FX, Li X, Lau VM-C, Zhu VZ (2021) To survive or to thrive? China's luxury hotel restaurants entering $\mathrm{O} 2 \mathrm{O}$ food delivery platforms amid the COVID-19 crisis. Internat. J. Hospitality Management 94:102855.

Yu L, Stafford G, Armoo AK (2005) A study of crisis management strategies of hotel managers in the Washington, DC metro area. Tourism Crises: Management Responses Theoretical Insight 91(2-3): 91-105.

Zahra A, Ryan C (2007) From chaos to cohesion-Complexity in tourism structures: An analysis of New Zealand's regional tourism organizations. Tourism Management 28(3):854-862.

Zemke V, Neal J, Shoemaker S, Kirsch K (2015) Hotel cleanliness: Will guests pay for enhanced disinfection? Internat. J. Contemporary Hospitality Management 27(4):690-710.
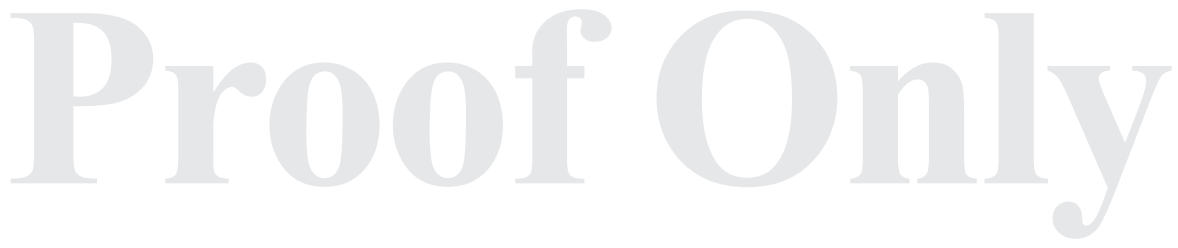


\section{AUTHOR QUERIES}

DATE $\quad 8 / 25 / 2021$

JOB NAME SERV

ARTICLE 20210282

QUERIES FOR AUTHOR_Le, Phi, and Le

\section{THIS QUERY FORM MUST BE RETURNED WITH ALL PROOFS FOR CORRECTIONS}

Q: 1_Per journal style, the short running headline, including the author names, must be fewer than 80 characters in total. Please revise accordingly (current $=88$ ).

Q: 2_Please provide all funding information, if applicable, including the names of the institutions as well as any grant numbers associated with the funding, or confirm that no funding was received.

Q: 3_Please confirm that the article title, author names, affiliations, and email addresses are set correctly. Please ensure that all affiliations include the city and the postcode.

Q: 4_Please confirm that keywords are correct as set.

Q: 5_Please confirm that heading levels are correct as set.

Q: 6_Please verify that all displayed equations and in-text math notations are set correctly.

Q: 7_Per INFORMS style, all variables should be italic and all vectors should be bold. Please confirm that all terms have been formatted properly throughout.

Q: 8_The in-text citation "Oxford Economics, 2020" is not in the reference list. Please correct the citation, add the reference to the list, or delete the citation.

Q: 9_The in-text citation " Mair et al. (2016)" is not in the reference list. Please correct the citation, add the reference to the list, or delete the citation.

Q: 10_The in-text citation "Moker et al. 2020" is not in the reference list. Please correct the citation, add the reference to the list, or delete the citation.

Q: 11_The in-text citation "Phi et al. 2014" is not in the reference list. Please correct the citation, add the reference to the list, or delete the citation.

Q: 12_Please ensure that all abbreviations are spelled out on first/only use, and please confirm those that have been done throughout.

Q: 13_The in-text citation "Scott et al., 2017" is not in the reference list. Please correct the citation, add the reference to the list, or delete the citation.

Q: 14_The in-text citation "Macau Daily Times, 2020" is not in the reference list. Please correct the citation, add the reference to the list, or delete the citation.

Q: 15_The in-text citation "Latin Finance, 2020" is not in the reference list. Please correct the citation, add the reference to the list, or delete the citation. 


\section{NUMBER 2 OF 3}

Q: 16_The in-text citation "Israeli et al. 2011" is not in the reference list. Please correct the citation, add the reference to the list, or delete the citation.

Q: 17_The in-text citation "Wynn, 2020" is not in the reference list. Please correct the citation, add the reference to the list, or delete the citation.

Q: 18_The in-text citation "Press Association (2020)" is not in the reference list. Please correct the citation, add the reference to the list, or delete the citation.

Q: 19_The in-text citation "Williams \& Price, 2020" is not in the reference list. Please correct the citation, add the reference to the list, or delete the citation.

Q: 20_The in-text citation "Vietnamnews, 2020" is not in the reference list. Please correct the citation, add the reference to the list, or delete the citation.

Q: 21_The in-text citation "STR, 2020" is not in the reference list. Please correct the citation, add the reference to the list, or delete the citation.

Q: 22_The in-text citation "Mulvihill \& Beaumont, 2020" is not in the reference list. Please correct the citation, add the reference to the list, or delete the citation.

Q: 23_The in-text citation "Hospitalitynet, 2020" is not in the reference list. Please correct the citation, add the reference to the list, or delete the citation.

Q: 24_The in-text citation "Rivera, 2020" is not in the reference list. Please correct the citation, add the reference to the list, or delete the citation.

Q: 25_The in-text citation "Maaty, 2020" is not in the reference list. Please correct the citation, add the reference to the list, or delete the citation.

Q: 26_The in-text citation "Mitroff \& Pearson, 1993" is not in the reference list. Please correct the citation, add the reference to the list, or delete the citation.

Q: 27_The in-text citation "Paraskevas \& Altinay, 2013" is not in the reference list. Please correct the citation, add the reference to the list, or delete the citation.

Q: 28_The in-text citation "Kucukusta et al. 2013" is not in the reference list. Please correct the citation, add the reference to the list, or delete the citation.

Q: 29_The in-text citation "Enz \& Way, 2016" is not in the reference list. Please correct the citation, add the reference to the list, or delete the citation.

Q: 30_The in-text citation "Davis et al. 2015" is not in the reference list. Please correct the citation, add the reference to the list, or delete the citation.

Q: 31_The in-text citation "Lee et al., 2015" is not in the reference list. Please correct the citation, add the reference to the list, or delete the citation.

Q: 32_The in-text citation "Susskind \& Curry, 2016" is not in the reference list. Please correct the citation, add the reference to the list, or delete the citation.

Q: 33_The in-text citation "Wang \& Ritchie, 2010" is not in the reference list. Please correct the citation, add the reference to the list, or delete the citation. 


\section{NUMBER 3 OF 3}

Q: 34_The in-text citation "Watanabe \& Mochimaru, 2017" is not in the reference list. Please correct the citation, add the reference to the list, or delete the citation.

Q: 35_Please include any necessary acknowledgments here.

Q: 36_Please ensure that all electronic references (URLs) include the accessed date.

Q: 37_Please ensure that the Felsenthal reference is correct and complete according to the type of material being cited.

Q: 38_Please ensure that all journal entries on the reference list include the volume and issue numbers and the page range. Please confirm any that have been added or updated.

Q: 39_Please ensure that all book entries on the reference list include the city of publication.

Q: 40_Reference "Zemke et al. 2015" is not cited in the text. Please add an in-text citation or delete the reference.

Q: 41_Please check that all tables and figures, including their titles and notes (which may contain edits) are set correctly.

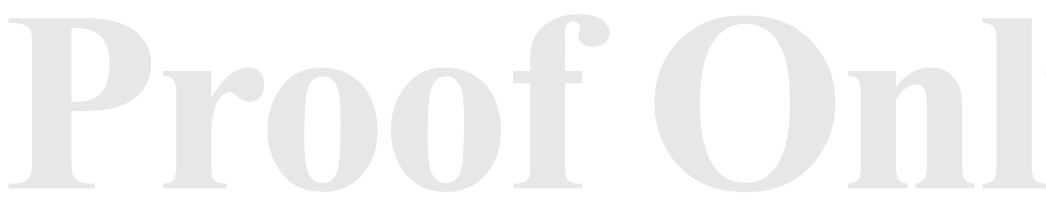

